\title{
PHOTOGRAMMETRIC DIGITAL SURFACE MODELS AND MOSAICED ORTHOIMAGERY FOR BARTER ISLAND, ALASKA
}

Stephen Escarzaga, Nicole E.M. Kinsman, and Jacquelyn R. Overbeck

\section{Raw Data File 2020-6}

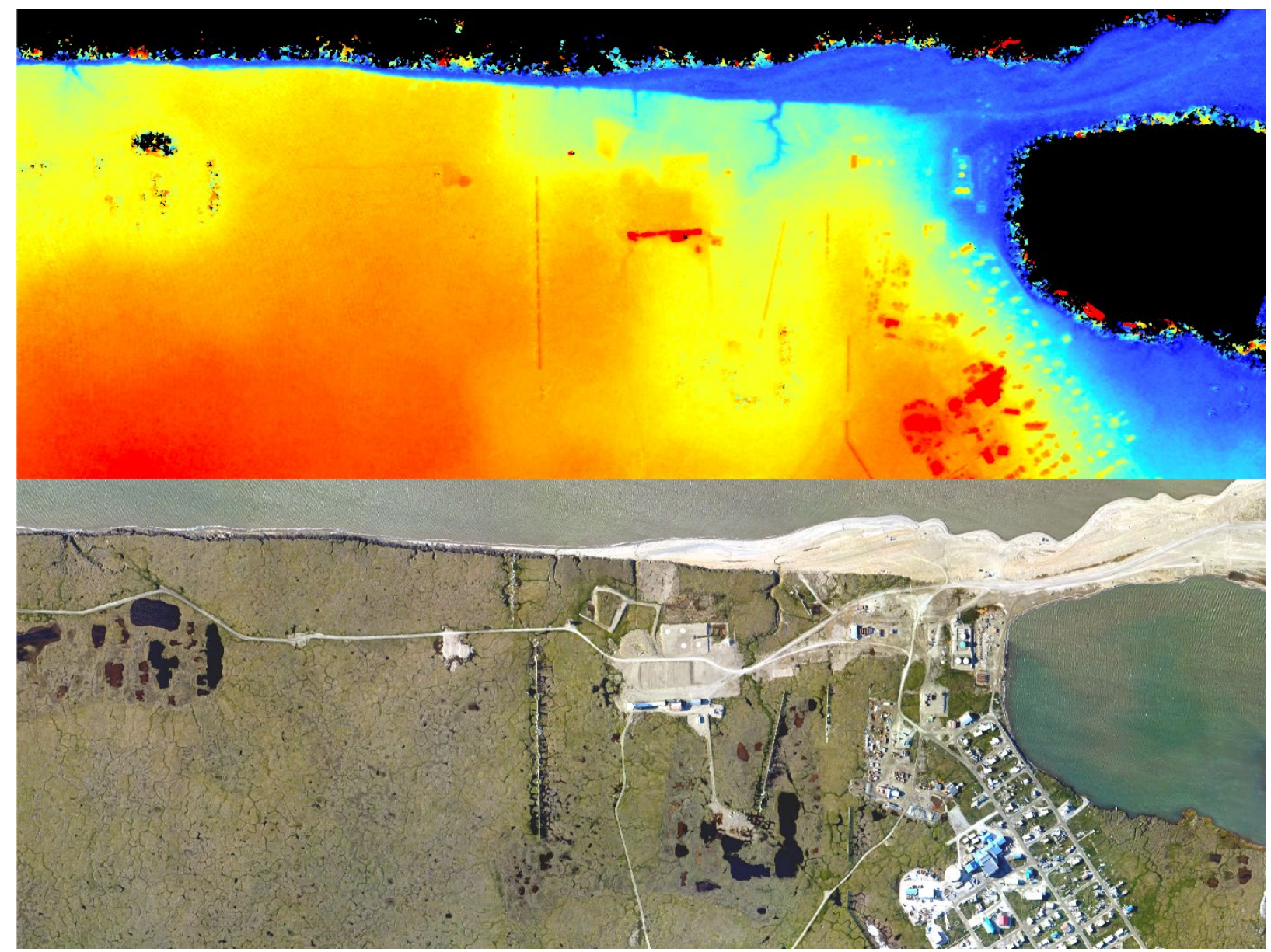

Digital surface model (top) and orthoimage (bottom) of Kaktovik and surrounding area.

This report has not been reviewed for technical content or for conformity to the editorial standards of DGGS.

2020

STATE OF ALASKA

DEPARTMENT OF NATURAL RESOURCES

DIVISION OF GEOLOGICAL \& GEOPHYSICAL SURVEYS
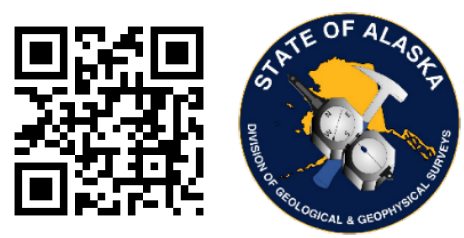


\title{
STATE OF ALASKA
}

Mike Dunleavy, Governor

\section{DEPARTMENT OF NATURAL RESOURCES}

Corri A. Feige, Commissioner

\section{DIVISION OF GEOLOGICAL \& GEOPHYSICAL SURVEYS}

Steve Masterman, State Geologist \& Director

Publications produced by the Division of Geological \& Geophysical Surveys are available to download from the DGGS website (dggs.alaska.gov). Publications on hard-copy or digital media can be examined or purchased in the Fairbanks office:

\author{
Alaska Division of Geological \& Geophysical Surveys (DGGS) \\ 3354 College Road | Fairbanks, Alaska 99709-3707 \\ Phone: 907.451.5010 | Fax 907.451.5050 \\ dggspubs@alaska.gov $\mid$ dggs.alaska.gov
}

DGGS publications are also available at:

Alaska State Library, Historical

Collections \& Talking Book Center

395 Whittier Street

Juneau, Alaska 99801

Alaska Resource Library and

Information Services (ARLIS)

3150 C Street, Suite 100

Anchorage, Alaska 99503

\section{Suggested citation:}

Escarzaga, Stephen, Kinsman, N.E.M., and Overbeck, J.R., 2020,

Photogrammetric digital surface models and mosaiced orthoimagery

for Barter Island, Alaska: Alaska Division of Geological \& Geophysical

Surveys Raw Data File 2020-6, 7 p. http://doi.org/10.14509/30456
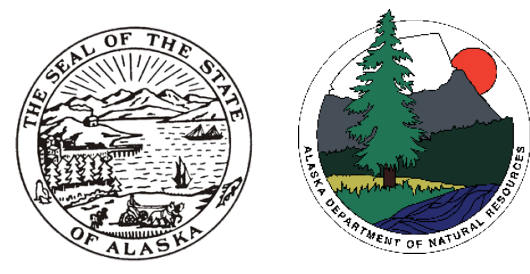


\title{
PHOTOGRAMMETRIC DIGITAL SURFACE MODELS AND MOSAICED ORTHOIMAGERY FOR BARTER ISLAND, ALASKA
}

Stephen Escarzaga ${ }^{1}$, Nicole E.M. Kinsman ${ }^{2}$, and Jacquelyn R. Overbeck ${ }^{3}$

\begin{abstract}
In 2017, the National Oceanic \& Atmospheric Administration (NOAA), National Geodetic Survey, Remote Sensing Division (RSD) performed extensive aerial collection of imagery along Alaska's northeastern coastline in support of NOAA's Coastal Mapping Program. Data collected under this initiative are typically used to improve maritime chart products, serve as a baseline for shoreline change monitoring, and update the national shoreline database. This report summarizes photogrammetric digital surface models (DSMs) and an orthomosaic derived from this image dataset using Structure from Motion (SfM) techniques for the Barter Island area. Aerial images used to derive products described in this report were collected on July 19, 2017. Ground control points (GCPs) and checkpoints used for vertical correction and validation of this data were collected with Global Navigation Satellite System (GNSS) surveys by the U.S. Geological Survey (USGS) on September 4, 2014, and September 18, 2016. This data collection is being released as a Raw Data File with an open enduser license and includes the following for the Barter Island area: (1) orthomosaic raster, (2) DSM raster, (3) smoothed DSM raster, and (4) DSM hillshade.
\end{abstract}

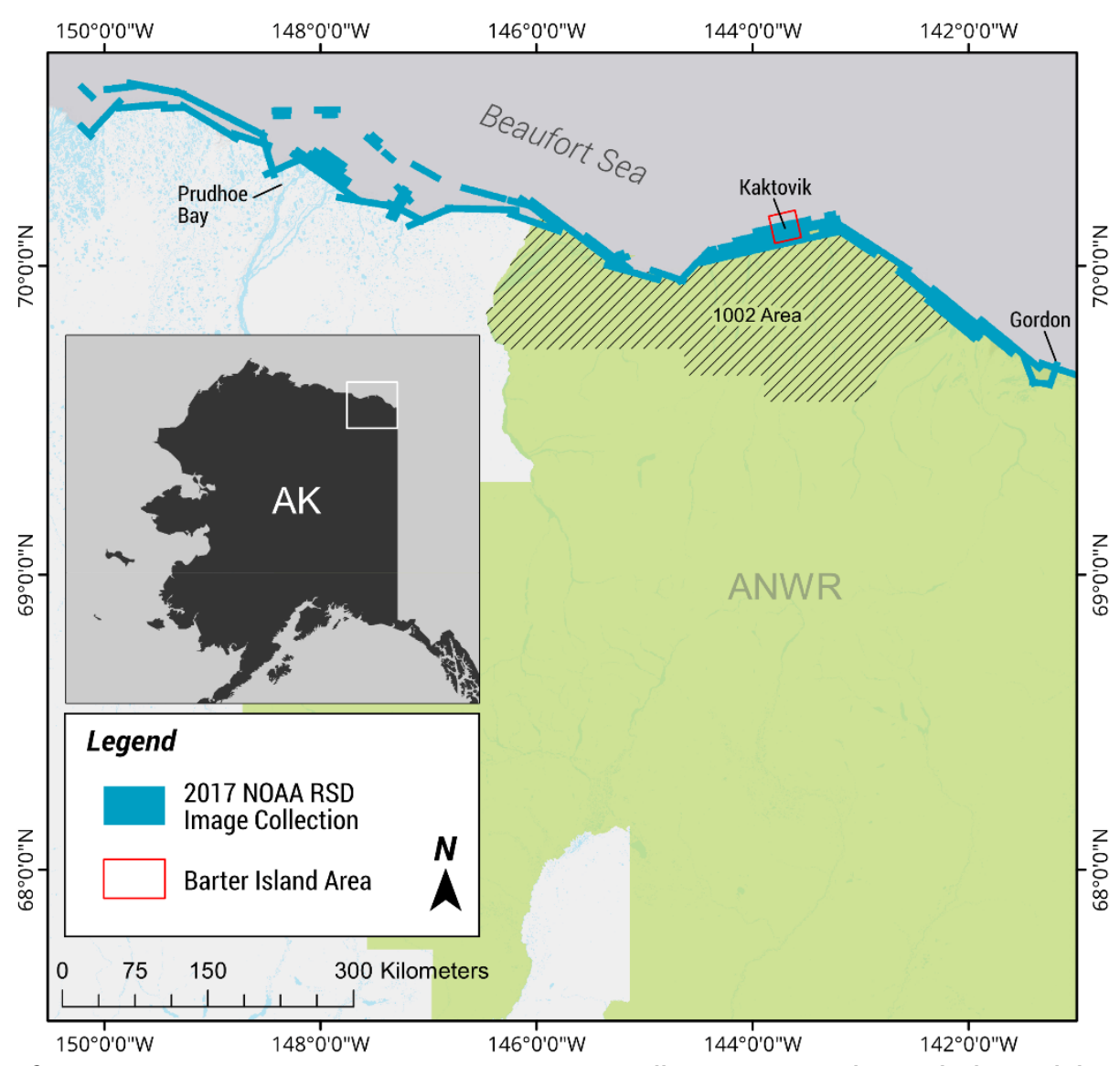

Figure 1. Overview of 2017 NOAA Remote Sensing Division image collections in northern Alaska and the Barter Island area of interest.

\footnotetext{
${ }^{1}$ National Oceanic \& Atmospheric Administration-CESSRST Scholar, University of Texas at El Paso, 500 W. University Ave, El Paso, TX 79968; smescarzaga@utep.edu

${ }^{2}$ National Geodetic Survey, National Oceanic and Atmospheric Administration, 222 W. $7^{\text {th }}$ Ave., Anchorage, AK 99513-7575

${ }^{3}$ Alaska Division of Geological \& Geophysical Surveys, 3354 College Road, Fairbanks, AK 99709-3707
} 


\section{DATA ACQUISITION}

NOAA RSD collected aerial imagery over the Barter Island area on July 19, 2017, from a Beechcraft King Air 350CER aircraft flying at a nominal altitude of $~ 2,286 \mathrm{~m}$ above ground level(AGL), resulting in an average $26 \mathrm{~cm}$ ground sampling distance (GSD) in the images. While many areas surveyed under the NOAA NGS Coastal Mapping Program are done with single flight lines, RSD planned the Barter Island survey to include multiple parallel lines providing $\sim 30$ percent image sidelap; images were captured every $\sim 8$ to 9 seconds, producing $\sim 60$ percent image endlap. In addition to nadir scenes, RSD also collected oblique images with two additional cameras in the fore and aft positions mounted at $\sim 33^{\circ}$ and $\sim 36^{\circ}$ view angles, respectively. For the nadir, fore, and aft aircraft ports, Applanix DSS SN580 cameras with focal lengths of $51.542 \mathrm{~mm}, 60.202 \mathrm{~mm}$, and $60.292 \mathrm{~mm}$ (respectively) collected 80.2 (nadir) and 39 (oblique) megapixel images in RAW format (table 1). Image capture between cameras was synchronized with each other and to an on-board Applanix POS/AV410 Global Navigation Satellite System (GNSS) and Inertial Measure Unit (IMU) system. The AeroAntenna GNSS antenna was mounted approximately $1.1 \mathrm{~m}$ above the camera ports.

Table 1. Camera system and image specifications for data used in product creation.

\begin{tabular}{|c|c|c|c|c|c|c|c|}
\hline & $\begin{array}{c}\text { Camera } \\
\text { Model }\end{array}$ & $\begin{array}{c}\text { Resolution } \\
\text { (pixels) }\end{array}$ & $\begin{array}{l}\text { File } \\
\text { Type }\end{array}$ & $\begin{array}{l}\text { Focal } \\
\text { Length }\end{array}$ & $\begin{array}{l}\text { Pixel } \\
\text { Size }\end{array}$ & $\begin{array}{l}\text { Coordinate } \\
\text { Reference } \\
\text { System }\end{array}$ & $\begin{array}{l}\text { Associated } \\
\text { Metadata }\end{array}$ \\
\hline Nadir & $\begin{array}{l}\text { Applanix } \\
\text { DSS SN580 }\end{array}$ & $10329 \times 7760$ & JPEG & $51.542 \mathrm{~mm}$ & $5.2 \times 5.2 \mu \mathrm{m}$ & $\begin{array}{c}\text { WGS84/UTM 7N/ } \\
\text { Orthometric } \\
\text { (EGM96) }\end{array}$ & $\begin{array}{c}\text { latitude, } \\
\text { longitude, } \\
\text { height \& omega, } \\
\text { phi, kappa }\end{array}$ \\
\hline $\begin{array}{l}\text { Fore } \\
\text { Oblique } \\
\left(33^{\circ}\right)\end{array}$ & $\begin{array}{l}\text { Applanix } \\
\text { DSS SN580 }\end{array}$ & $7212 \times 5480$ & JPEG & $60.202 \mathrm{~mm}$ & $6.8 \times 6.8 \mu \mathrm{m}$ & $\begin{array}{c}\text { WGS84/UTM 7N/ } \\
\text { Orthometric } \\
\text { (EGM96) }\end{array}$ & $\begin{array}{c}\text { latitude, } \\
\text { longitude, } \\
\text { height \& omega, } \\
\text { phi, kappa }\end{array}$ \\
\hline $\begin{array}{l}\text { Aft } \\
\text { Oblique } \\
\left(37^{\circ}\right)\end{array}$ & $\begin{array}{l}\text { Applanix } \\
\text { DSS SN580 }\end{array}$ & $7212 \times 5480$ & JPEG & $60.295 \mathrm{~mm}$ & $6.8 \times 6.8 \mu \mathrm{m}$ & $\begin{array}{c}\text { WGS84/UTM 7N/ } \\
\text { Orthometric } \\
\text { (EGM96) }\end{array}$ & $\begin{array}{c}\text { latitude, } \\
\text { longitude, } \\
\text { height \& omega, } \\
\text { phi, kappa }\end{array}$ \\
\hline
\end{tabular}

\section{DATA PROCESSING}

Airborne GNSS and IMU data were processed using Applanix’s PosPac MMS 8.0 commercial software by technicians and cartographers within RSD. Due to the remoteness of the survey area, a satellite-derived, real-time extended positioning method with no static base station was used for post-processing. Total Propagated Uncertainty for the resultant positional data is $66 \mathrm{~cm}$. GPS data were adjusted to the World Geodetic System 1984 (WGS84) reference frame (mapping epoch of 2017.542466), and heights referenced to the Earth Gravitational Model of 1996 (EGM96) (table 1). 
Photos were individually processed along with dark current images to remove inherent sensor noise. Raw images from the sensor (.RAW format) were processed to JPEG format to accommodate the transfer and subsequent SfM processing of this data. Batch color correction of oblique JPEGs was then conducted in Adobe Photoshop to more closely match the color profile of nadir images.

Positional (latitude, longitude, height) and rotational (phi, kappa, omega) data from the on-board GPS/IMU system were supplied in additional metadata files, each pertaining to a specific camera location and rotation in space and time. These data fields were programmatically copied from the metadata documents into one camera external orientation file used in SfM processing within Agisoft Metashape Professional. Orthometric camera heights in the external orientation file were converted to ellipsoidal heights (WGS84) using NOAA's VDatum conversion tool. A total of 144 images were used in the SfM processing (50 nadir and 94 oblique), in which computer vision algorithms create a three-dimensional terrain model from overlapping sections of image data. The final orthomosaic is a result of orthometric correction of the images using this terrain model and a subsequent mosaicking of these orthoimages. Figure 2 summarizes the data preprocessing and SfM procedure/parameters used to create these final products.

\section{DATA PRODUCTS}

The data products for the Barter Island project area include the following: (1) orthomosaic raster, (2) DSM raster, (3) smoothed DSM raster, and (4) DSM hillshade raster. These data are stored in the WGS84 (mapping epoch of 2017.542466) reference frame, projected in Universal Transverse Mercator (UTM) Zone 7 North, with heights referenced to the ellipsoid (WGS84).

\section{Orthomosaic}

The orthomosaic is a 3-band, 8-bit unsigned integer raster file (red/green/blue; file format GeoTIFF) with a GSD of $26 \mathrm{~cm}$ (fig. 3A). NoData values for each band have been set to 0 . The file employs Lempel-Ziv-Welch (LZW) compression and total uncompressed file size is 3.19 GB.

\section{Digital Surface Model (DSM)}

The DSM is a 1-band, 32-bit floating point integer raster file (file format GeoTIFF) with a GSD of $53 \mathrm{~cm}$. DSM raster cell values represent elevation values at any given point. NoData values have been set to $-3.40282346639 \mathrm{e}+038$. The uncompressed file size is $2.16 \mathrm{~GB}$.

\section{Smoothed Digital Surface Model (DSM)}

The smoothed DSM is a 1-band, 32-bit floating point integer raster file (file format GeoTIFF) with a GSD of $53 \mathrm{~cm}$. This DSM was created from a smoothed 3D mesh, rather than a dense point cloud. 3D mesh creation and subsequent smoothing was done in Agisoft Metashape. Smoothing here removes much of the inherent low-noise in surface features that exist in the normal DSM (fig. 4). DSM raster cell values represent elevation values at any given point. NoData values have been set to $-3.40282346639 \mathrm{e}+038$. The uncompressed file size is $1.42 \mathrm{~GB}$. 


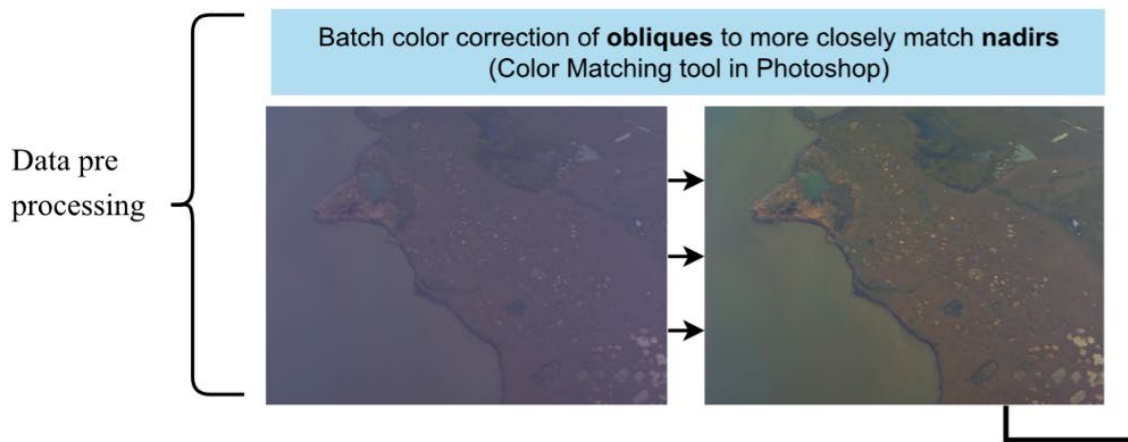

(Color Matching tool in Photoshop)

Data pre

processing

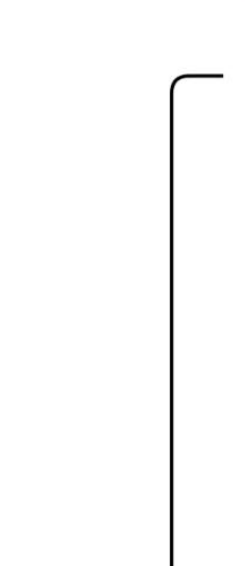

Agisoft

Metashape

Processing

\section{Photo Aligning}

- Input focal length and pixel size (pulled from .geom file)

- Fix camera calibration parameters

- Align cameras with:

- Accuracy: High

- Generic and Reference Preselection: On

- Key Point Limit: 60,000

- Tie Point Limit: 0

- Adaptive Camera Model Fitting: On

\section{Error Reduction / Optimization}

- Un-fix camera calibration

- Optimize Cameras w/: cx, cy, k1, k2, k3, p1, p2
Python script to extract and format Lat, Lon, Height and Phi, Kappa,

Omega values from each image's associated geom file

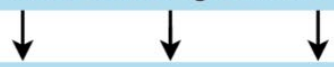

Convert orthometric heights in .geom (geoid12b) to WGS Ellipsoid (VDatum)

\section{Oblique + Nadir Scenes}

(144 cameras)

- Perform gradual selection error reduction with camera optimization between each run

- Reconstruction uncertainty: level of 10

- Projection accuracy: level of 2.3

- Optimize with all coefficients except for focal length

- Reprojection error: level of 0.3
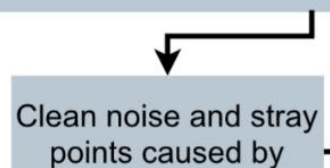

Build Dense Cloud water

- Quality: Ultra High

- Depth Filtering: Mild

Build Mesh

- Surface Type: Height Field

- Interpolation: Disabled

- Face Count: High

\section{Build Ortho}

- Source: DEM

- Interpolation: Enabled
Build DEM

- Source: Dense Cloud or Mesh

- Interpolation: Disabled
Smooth Mesh

- Strength: 3

Figure 2. Diagram detailing the steps and parameters used within the SfM processing procedure. 


\section{DSM Hillshade}

The DSM hillshade is a 3-band, 8-bit unsigned integer raster file (red/green/blue; file format GeoTIFF) with a GSD of $53 \mathrm{~cm}$ (fig. 3B). It represents hillshading of the unsmoothed DSM raster. NoData values have been set to 255. The file employs LZW compression. The hillshade was produced using the Image Analysis tools within ArcGIS Desktop (ArcMap 10.4). The uncompressed file size is 1.62 GB.
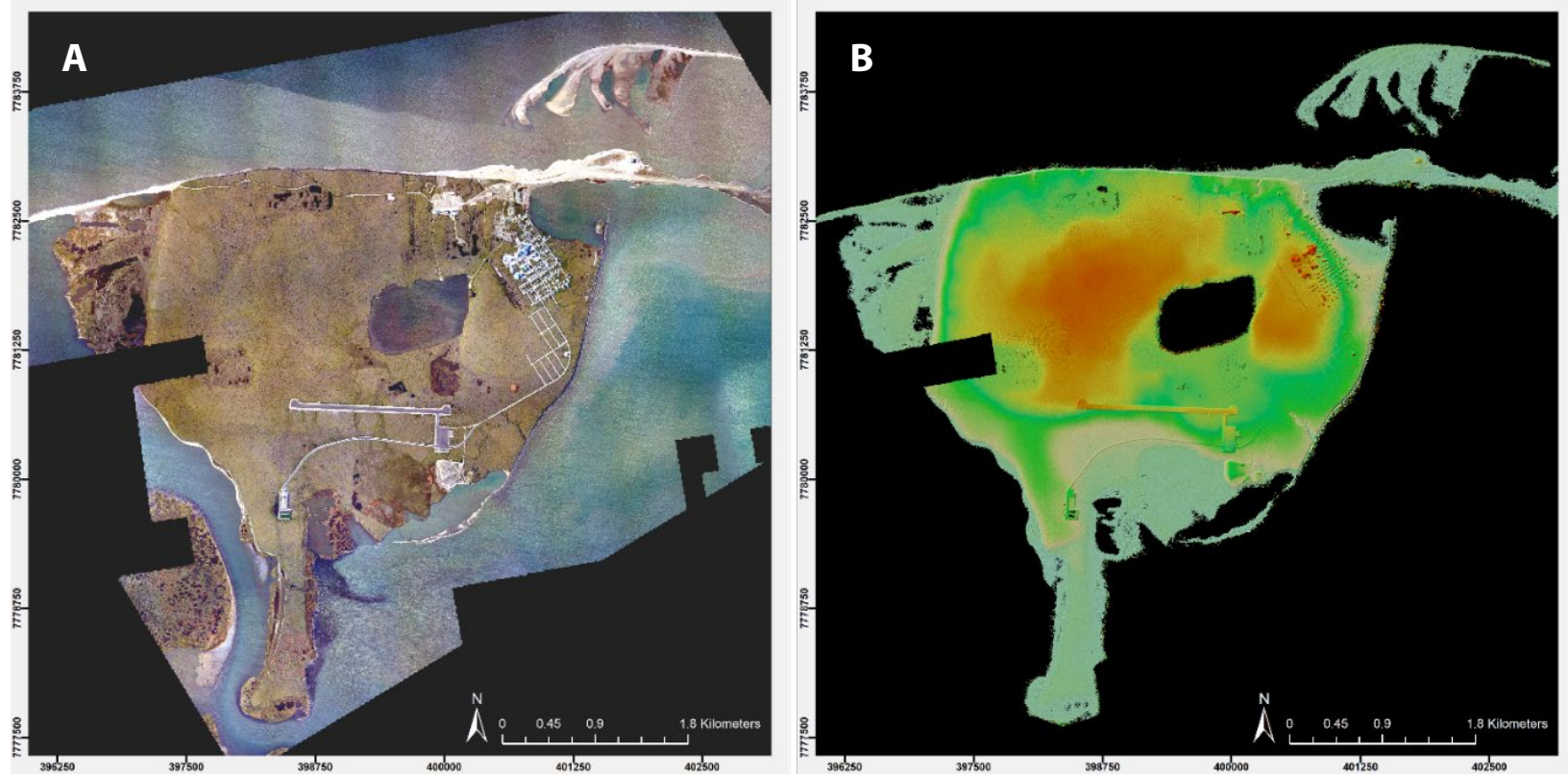

Figure 3. A. RGB orthomosaic of Barter Island included in this data release. B. DSM hillshade of Barter Island included in this data release.

\section{DATA QUALITY}

The original airborne imaging survey design for this dataset was optimized to support orthomosaic production and subsequent 2D feature extraction (e.g., shoreline position). The planned image endlap and sidelap (60 percent and 30 percent, respectively) is on the extreme low end for SfM production and is more characteristic of traditional photogrammetric applications.

The unsmoothed DSM included here contains inherent low noise in surface values (on the order of 25 to $30 \mathrm{~cm}$ ) throughout areas presumed to be flat. This noise is most likely a product of the collection parameters and use of compressed JPEGs as opposed to TIFFs. Figure 4 shows a comparison of surface elevation profiles between the smooth and unsmoothed DSMs along a section of the graded-gravel airport runway. Other DSM anomalies include concentric rings in surface elevation (an SfM processing artifact most likely caused by suboptimal image overlap), and high noise in surface elevation over areas of water caused by the SfM algorithm's inability to match features between image pairs where water is present (fig. 5).

Ground control points (GCPs) were supplied by the U.S. Geological Survey (USGS) Pacific Coastal \& Marine Science Center from field reconnaissance on September 4, 2014, and September 18, 2016, with an 
Ashtech Z-Extreme GNSS system. A subset of 200 GCPs were used to evaluate these photogrammetric products, with 100 used to determine a mean vertical offset (as control) and 100 to determine residual error after vertical transformation (as checkpoints). Of this subset, only two GCPs were photo-identifiable. A welldistributed network of photo-identifiable GCPs is typically used to determine the horizontal accuracy of orthomosaics and co-located DSMs. Due to the lack of photo-identifiable GCPs in this porject, no horizontal transformation has been applied to the data. However, in the two locations where these GCPs do exist, the orthomosaic showed an estimated $20 \mathrm{~cm}$ and $25 \mathrm{~cm}$ offset in the easting direction.

Vertical accuracy was determined for both the smoothed and unsmoothed DSMs. Accuracies were determined by calculating the mean vertical offset between DSMs and 100 GCPs, reducing this mean offset to zero by applying a vertical transformation and then determining a vertical Root Mean Square Error (RMSEz) for the transformed surfaces using the 100 checkpoints. Table 2 shows a summary of DSM accuracy statistics. The unsmoothed DSM had a mean vertical offset of $+5 \mathrm{~cm}$, and the final unsmoothed DSM had an RSMEz of $13.7 \mathrm{~cm}$ with +/- one standard deviation of $11.3 \mathrm{~cm}$; 95 percent of checkpoints fell within $26 \mathrm{~cm}$. The smoothed DSM had a mean vertical offset of $+8 \mathrm{~cm}$ and the final smoothed DSM had an RMSEz of 13.3 $\mathrm{cm}$ with + /- one standard deviation of $8.5 \mathrm{~cm} ; 95$ percent of checkpoints fell within $28 \mathrm{~cm}$.

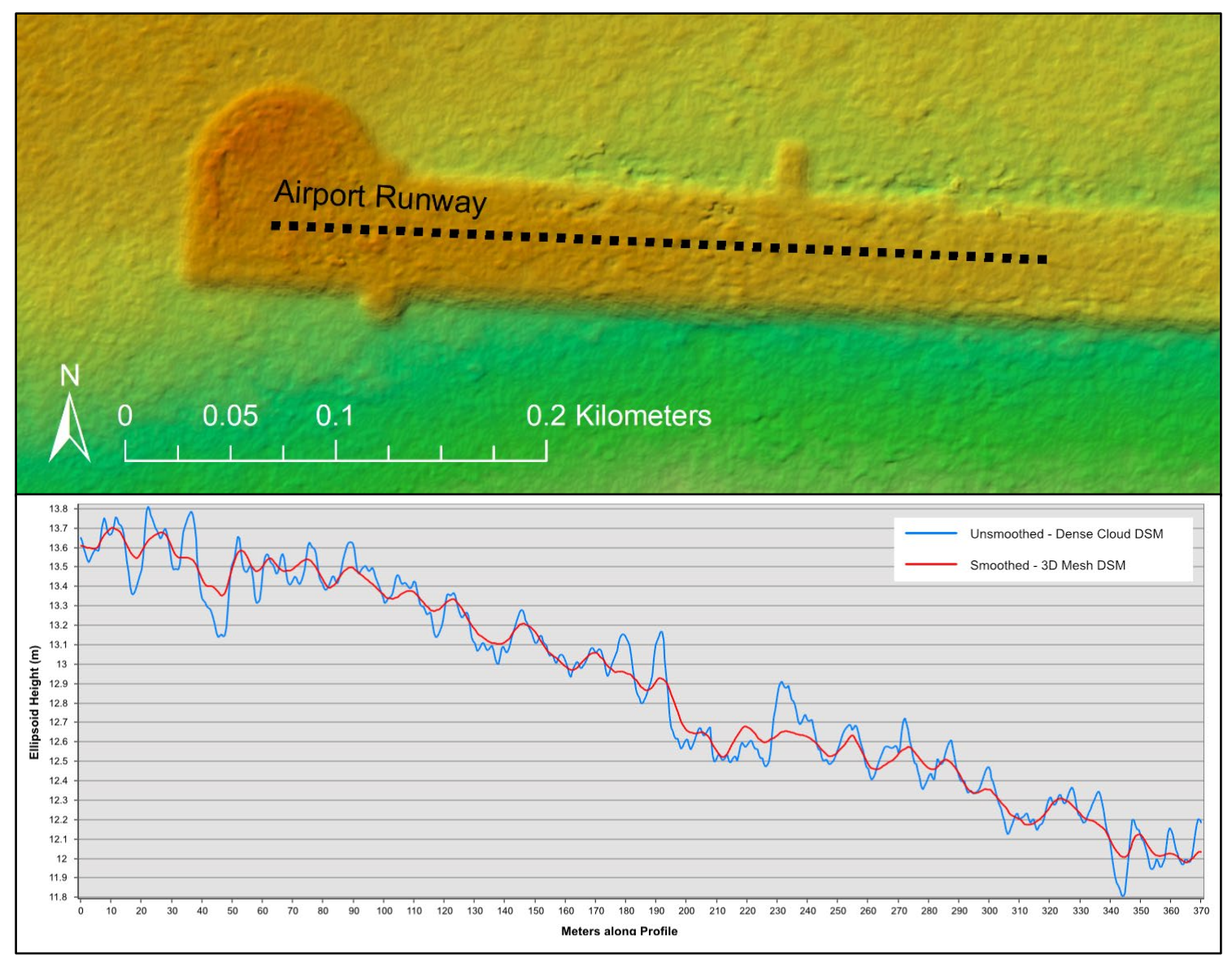

Figure 4. (Top) Map showing the hillshade DSM with elevation profile location (dashed black line). (Bottom) Elevation profile showing the unsmoothed DSM (blue) and smoothed DSM (red). 


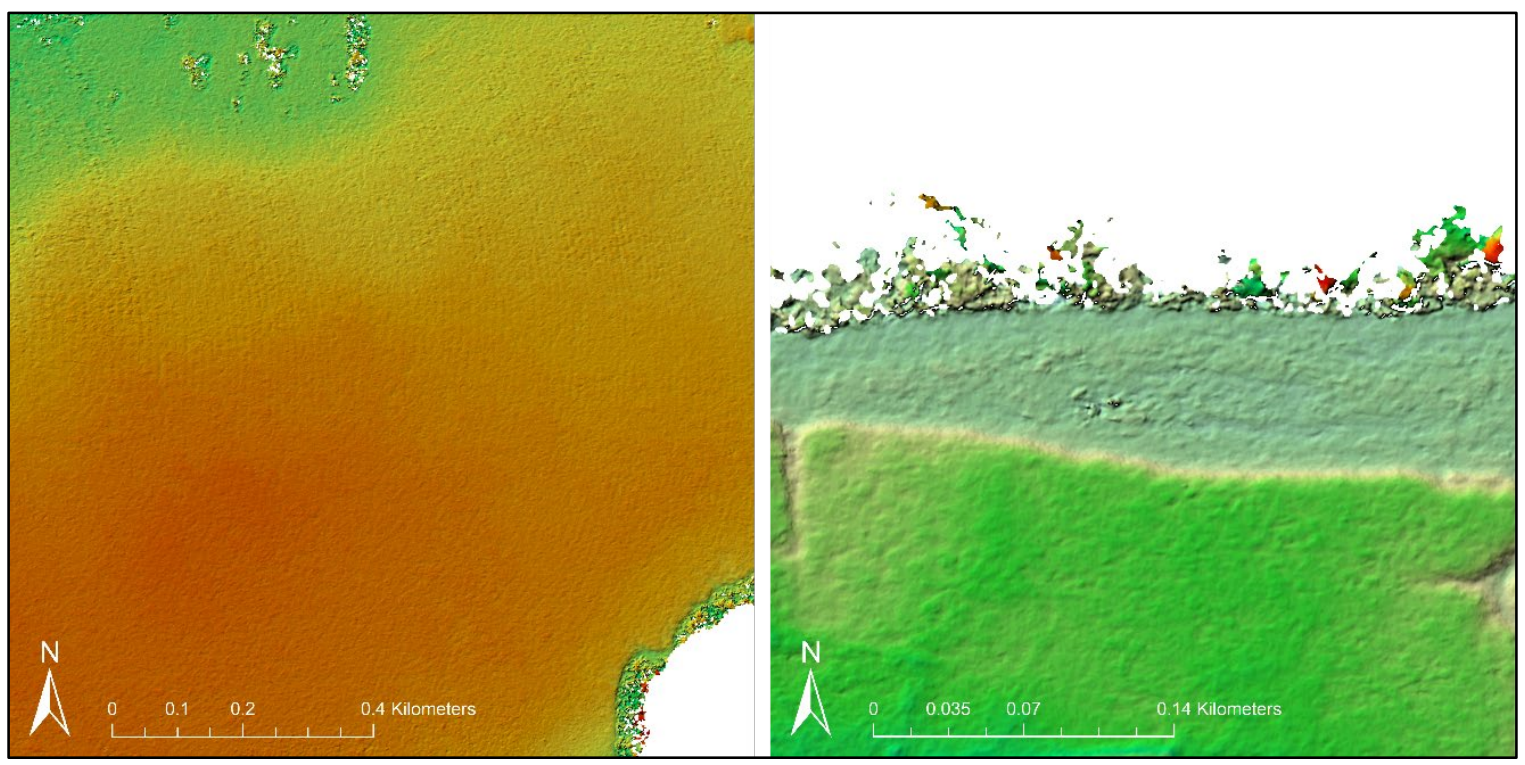

Figure 5. Maps of processing artifacts. (Left) Hillshade DSM showing an example of concentric ring features. (Right) Hillshade DSM showing high noise over water at the coast in northern portion of image.

Table 2. Summary statistics for vertical accuracies of unsmoothed and smoothed DSMs.

\begin{tabular}{|l|c|c|c|c|}
\hline & $\begin{array}{c}\text { Number of } \\
\text { GCPs/Checkpoints }\end{array}$ & $\begin{array}{c}\text { Mean Vertical } \\
\text { Offset }\end{array}$ & Final RMSEz & $\begin{array}{c}\text { Standard } \\
\text { Deviation } / \text { 95 }^{\text {th }} \\
\text { Percentile }\end{array}$ \\
\hline $\begin{array}{l}\text { Unsmoothed } \\
\text { DSM }\end{array}$ & $103 / 32$ & $5 \mathrm{~cm}$ & $13.7 \mathrm{~cm}$ & $11.3 \mathrm{~cm} / 26 \mathrm{~cm}$ \\
\hline $\begin{array}{l}\text { Smoothed } \\
\text { DSM }\end{array}$ & $103 / 32$ & $8.5 \mathrm{~cm}$ & $13.3 \mathrm{~cm}$ & $8.5 \mathrm{~cm} / 28 \mathrm{~cm}$ \\
\hline
\end{tabular}

\section{ACKNOWLEDGMENTS}

This project is supported and monitored by the National Oceanic and Atmospheric Administration Cooperative Science Center for Earth System Sciences and Remote Sensing Technologies (NOAA-CESSRST) under the Cooperative Agreement Grant \#NA16SEC4810008. The authors would like to thank The City College of New York, NOAA-CESSRST (aka CREST) program and NOAA Office of Education, Educational Partnership Program for full fellowship support of Stephen M. Escarzaga. Stephen M. Escarzaga would like to thank his advisor Craig Tweedie, NOAA mentors Nicole Kinsman, Jon Sellars, Jason Woolard with the National Geodetic Survey, and Ann Gibbs with the Pacific Coastal and Marine Science Center of the USGS for their guidance and contributions to this work. Additional acknowledgments for technical guidance go to Jeff Sloan (USGS), John Warrick (USGS), Ben Jones (USGS), Tahzay Jones and Chad Hults (NPS), Tom Noble, Gennady Gienko (UAF), and Mike R. James (Lancaster University).

The views and conclusions contained in this document are those of the authors and should not be interpreted as representing the opinions or policies of the funding agency or U.S. Government. Mention of trade names or commercial products does not constitute their endorsement by the U.S. Government. 